\title{
What Do People Say Is the Most Important Reason to Protect Nature? An Analysis of Pro-Environmental Motives Across 11 Countries
}

\author{
*the version of record is now published in Journal of Environmental Psychology*
} DOI: 10.1016/j.jenvp.2022.101762

\author{
Abel Gustafson \\ University of Cincinnati \\ Shelby Singh \\ University of Cincinnati
}

\author{
Amanda Pace \\ University of Cincinnati \\ Matthew H. Goldberg \\ Yale University
}

\begin{abstract}
Using open-ended responses from 5,297 interviews across 11 countries, this study reports what people say are the most important reasons to protect nature. Overall, and in some individual countries (e.g., Brazil, China, South Africa, South Korea, United States), the most frequently stated reason was an anthropocentric motive of ensuring human health and survival. But in some countries (e.g., Kenya, United Kingdom, Indonesia), ecocentric and altruistic motives - such as maintaining balance in nature's delicate interconnected system or protecting nature for future generations - were more common.
\end{abstract}

Data, codebook, supplementary material: $\underline{\text { https://osf.io/9xnz8 }}$

Keywords: environmental psychology, pro-environmental behavior, international survey, public opinion, qualitative research, thematic analysis

Much research has applied theoretical models of behavior (e.g., Ajzen, 1991) to environmental topics, often highlighting the importance of antecedent constructs like "pro-environmental attitudes" and

Correspondence concerning this paper should be addressed to Abel Gustafson, School of Communication, Film, \& Media Studies, University of Cincinnati, Cincinnati, OH, 45211. Email: gustafae@uc.edu

The 2nd and 3rd authors (AP; SS) contributed equally to this study. This work was supported by the National Geographic Society as part of the Valuing Nature project. This project was made possible by the work and collaboration of Jonathan Rodkin and the Measurement, Evaluation \& Research team of the National Geographic Society. This preprint template was made available by Brenton M. Wiernik (https://osf.io/hsv6a/)

"environmental concern." Environmental attitude has been defined as the level of favorability or importance with which a person sees the natural environment (Milfont \& Duckitt, 2010), and environmental concern is their worry about it (Fransson \& Gärling, 1999; Milfont, 2007).

Yet both of these concepts require some underlying motive(s). Why is the environment important? Why should we be concerned about threats to it? Why protect or prioritize nature at all? Absent an answer to these fundamental questions, pro-environmental attitudes and environmental concern are detached from the driving force that creates and sustains them. The present study investigates these underlying motives and their relative prevalence across diverse countries.

The plausible reasons to protect or care for nature are numerous and diverse. They include anthropocentric (human-centered) reasons, such as protecting nature to ensure the health and well-being of humans, or so humans can continue to enjoy its beauty. Other potential rationales are more ecocentric, such as protecting nature in order to prevent the extinction of plant and animal species, or because of a belief that nature has its own autonomy and rights.

These diverse motives occupy general categories such as environmental goals (to protect or enhance the environment), hedonic goals (to feel good), normative goals (to act according to social norms or rules), and gain goals (to acquire resources or meet one's needs; Lindenberg \& Steg, 2007; Steg et al., 2014; Stern, 2000). Similarly, Chan et al. (2016) describe three different possible sources of nature's value: "instrumental value" (it gives us benefits), "intrinsic value" (nature has its own independent value), and "relational value" (our relationship with nature has moral value). Others have made similar distinctions between "preservation" and "utilitarian" motives (e.g., 
Bogner \& Weisman, 1999). Recent survey research has shed further light on pro-environmental motives by reporting how Americans rate the importance of each of 16 reasons to transition to renewable energy (e.g., "Reduce air pollution," "Create jobs and a stronger economy;" Gustafson et al., 2020) and 11 reasons to reduce global warming (e.g., "Improve people's health," "Save many plant and animal species from extinction;" Goldberg et al., 2019).

However, most research studying these rationales, motives, values, and goals has used closed-ended response options chosen by the researchers. This approach constrains and determines the possible findings (Foddy 1993; Pew, 2021; Lazarzfeld, 1944), such that these studies can only find the prevalence of reasons to protect nature that the researchers already decided should be included as response options. This limitation highlights the advantages of open-ended qualitative responses, in which people can express any opinion and do so in their own words (Foddy 1993; Lazarzfeld, 1944). Although this approach is common and valuable in qualitative research, the findings from most of these qualitative studies are non-generalizable due to their frequent use of small non-representative samples.

A further limitation of the existing body of research is that most has been conducted only within individual countries - often the United States or a western European country. This constrains our understanding of human environmental psychology, since people's primary motives for protecting nature may vary substantially across cultures and countries. Further, effective communication strategies are often developed from an understanding of the values, beliefs, and motives of an audience (e.g., Goldberg, Gustafson, Rosenthal, \& Leiserowitz, 2021; Hurst \& Stern, 2020; Luong, Garrett, \& Slater, 2019; Wolsko, Ariceaga, Seiden, 2016). Thus, communication campaigns across the world could benefit from information about which reasons to protect nature are seen as most important by a particular target audience, because they could then tailor their messaging to resonate with those motives.

In sum, it is imperative to inform the crucial question of what people say are the most important reasons to protect nature with a study using open-ended responses, from large high-quality samples, representing many diverse cultures. These were the aims of the present study. Specifically, we investigated:

RQ1: What types of reasons do people state as being their most important reason(s) for protecting nature?
RQ2: How do the identified types of reasons to protect nature vary in their frequency?

RQ3: How do countries vary in the frequency with which each of the identified types of reasons to protect nature is stated?

\section{Methods}

\section{Data Collection and Measures}

To inform these research questions, we used data from a large international survey $(\mathrm{N}=12,000)$ measuring public opinion on environmental topics among adults in 12 countries (Australia, Brazil, China, India, Indonesia, Kenya, Mexico, South Africa, South Korea, the United Arab Emirates, the United Kingdom, and the United States), with 1,000 general population respondents per country. The survey was designed by the National Geographic Society (NGS), and measured a wide range of beliefs about nature and environmental issues, as well as pro-environmental behaviors. Ipsos conducted the sampling, recruitment, and administration of the survey in January of 2019. After the survey was fielded, the authors were invited by NGS to collaborate in analyzing and publishing findings from these data.

The survey was conducted in a language chosen by each respondent, and one of the questions asked "What do you think is the most important reason that we should protect nature?" Respondents answered in their own words, in a language of their choice. The responses were translated to English by Ipsos. The original responses and their English translations are available in the full dataset on our study's Open Science Framework (OSF) page (blinded link for peer review: https://osf.io/9xnz8/?view_only=e3fdb6f563bd4f2f8e 9212cb5341486e).

In the United States, United Kingdom, and Australia, the study was performed fully online and the samples can be considered representative of the national adult population. Due to low internet penetration, Ipsos used a mix of face-to-face and online modes to achieve representative samples in South Africa, South Korea, and the UAE. For the same reason, Ipsos used only face-to-face interviews in Kenya and India. However, the samples from Mexico, China, Brazil, Indonesia, and South Africa should be considered representative only of the online population because in these five countries there is relatively low internet penetration (50-60\%) yet Ipsos relied heavily on fully online methods.

In the total sample used for analysis (all 11 countries combined), $51 \%$ of respondents identified as male, and $49 \%$ identified as female. The mean age was 
$40.88(\mathrm{SD}=15.14, \min =18, \max =94)$ with $16 \%$ between $18-24,24 \%$ between $25-34,21 \%$ between $35-44$, $16 \% 45-54$, and $23 \% 55$ or older. Additional demographic information, including descriptive statistics for individual countries, is reported in the online supplement.

\section{Analysis}

To develop the typology of reasons and inform RQ1, the research team conducted a thematic analysis (Clarke \& Braun, 2005) using a random 5\% "training subsample" $(n=600)$ of the open-ended responses. A thematic analysis identifies the major themes or categories that are represented in a set of texts. Applied here, the goal was to develop a typology that identifies the general types of reasons to protect nature occurring in the open-ended responses, and with what frequency each of those types occurs.

In this process, three of the authors identified the most basic theme of each response in this training subsample, such that common themes (general types of reasons to protect nature) emerged. Through several iterations - working first independently and then collaboratively to resolve discrepancies - the authors formalized a codebook detailing 12 distinct types of reasons and how to differentiate them. Two additional types of valid responses to the question ("Don't Know" and "Opposed") and labels for four distinct types of missing, irrelevant, or indecipherable responses were also identified. Table 1 describes each emerging type of reason to protect nature and provides exemplar responses. The supplementary materials contain a codebook describing the full typology development and data coding process, as well as detailed instructions and decision rules for human coders. Two of the authors were trained to label open-ended responses in accordance with this typology and demonstrated good inter-rater reliability (Krippendorf's $\mathrm{a}=.81$ ) in a blind test.

For the main analysis, a random half of the responses in the dataset were selected $(N=6,000)^{1}$ and were randomly split between the two coders, with the country and demographic data being obscured from the coders. The coders read each of their assigned openended responses and recorded the reason(s) to protect nature communicated by it, according to the coding definitions, rules, and procedures detailed in the codebook. About $19 \%$ of responses expressed multiple distinct types of reasons according to the coding system,

\footnotetext{
${ }^{1}$ We chose to not analyze the remaining 5,400 responses in the dataset because (a) we already achieved thematic saturation, and (b) we do not see significant practical value in powering our study to
}

so for those responses multiple types of reasons were recorded.

Before conducting the final analyses, the coded responses were inspected for duplicates - as it appeared that there were occasional instances of repetition that were unlikely to happen by chance. Our data cleaning procedure and its findings are documented in detail in the supplemental materials. We found that this issue was by far most common in the India sample which led us to exclude it entirely from analyses. We also removed all other cases considered unlikely to be genuine unique responses, leaving data from 11 countries $(N=$ 5,297 ) for analysis.

To inform RQ2 and RQ3, we calculated the proportional frequency with which each type of reason to protect nature occurred in the full international sample (RQ2) as well as in the responses within each individual country (RQ3). At the 95\% confidence level, the average margin of error for the proportions in the figures and tables is about $1 \%$ in the international sample and about $5 \%$ within individual countries.

Figure 1 reports the main results, but for parsimony omits the two least frequently reported types of reasons to protect nature ("Irreplaceability" and "Nature's Autonomy") and two additional types of valid responses ("Opposed" and "Don't Know") because none of those types were found in more than $4 \%$ of responses in any country. The complete proportional frequencies of all types of responses are reported in the supplementary materials. The calculation of the proportions reported in Figure 1 excluded responses coded only as "Refused" (e.g., missing), "Vague" (e.g., "it is important"), "Unclear" (e.g., indecipherable text), or "Solutions" (e.g., "we must take action immediately"), because those types of responses do not answer the question that was asked.

\section{Results and Discussion}

Informing RQ1, the thematic analysis of the openended responses yielded 12 distinct types of reasons to protect nature (Table 1). They included familiar ecocentric motives such to maintain or increase the health and quality of our general natural environment, broadly construed ("Environmental Health"), and to protect or benefit non-human animal species and plants in particular ("Protect Plants \& Animals"). There were also frequent mentions of anthropocentric motives for protecting nature, such as to ensure human's access to natural resources that we want or need (fuel, food, materials),

achieve confidence in differences smaller than five percentage points. A more detailed rationale is given in the supplementary materials. 
or to enable us to continue to enjoy nature's aesthetic beauty and generally improve our quality of life ("Human Enjoyment").

Some of the types of reasons (Table 1) clearly correspond with the general goals and values motivating proenvironmental behavior that have been noted in previous. For example, hedonic goals (Steg et al., 2007; 2014) and instrumental values (Chan et al., 2016) likely motivate many responses labeled as "Human Enjoyment"as do gain goals and instrumental values for "Human Resources."
However, some of the emerging types of reasons were relatively unanticipated and novel, highlighting the value of this open-ended response format. For example, the main theme of many responses was that the most important reason to protect nature is to preserve it for the sake of future generations ("Future"). Also, many responses focused on the theme that nature is a delicate, interconnected balance and negatively affecting one aspect of nature can cause cascading effects through the interconnected system ("Connected System").

Table 1

Typology of Reasons to Protect Nature in the Open-Ended Responses

\begin{tabular}{|c|c|c|}
\hline Response Labels & Description & Examples from Data \\
\hline Reasons to Protect Nature & $\begin{array}{l}\text { The most important reason to protect } \\
\text { nature is... }\end{array}$ & \\
\hline Environmental Health & $\begin{array}{l}\text { General health and quality of environ- } \\
\text { ment, atmosphere, outdoors. }\end{array}$ & $\begin{array}{l}\text { "For a healthy planet," "Avoid air pollu- } \\
\text { tion," "To preserve it" }\end{array}$ \\
\hline Connected System & $\begin{array}{l}\text { Everything is interconnected; Do not } \\
\text { upset the balance, equilibrium, or har- } \\
\text { mony within nature. }\end{array}$ & $\begin{array}{l}\text { "Everything's connected," "To keep bal- } \\
\text { ance," "We are part of it," "To coexist in } \\
\text { harmony" }\end{array}$ \\
\hline Protect Plants \& Animals & $\begin{array}{l}\text { The health of non-human animal and } \\
\text { plant species (specifically) }\end{array}$ & $\begin{array}{l}\text { "To prevent the extinction of endan- } \\
\text { gered animals" "Save trees" }\end{array}$ \\
\hline Climate \& Disaster & $\begin{array}{l}\text { To mitigate climate change and/or dis- } \\
\text { asters (e.g., floods, droughts) }\end{array}$ & $\begin{array}{l}\text { "Global warming," "Prevent natural dis- } \\
\text { asters" }\end{array}$ \\
\hline Nature's Autonomy & $\begin{array}{l}\text { Nature has its own rights, agency, } \\
\text { takes precedence, or may retaliate }\end{array}$ & $\begin{array}{l}\text { "Nature was here first," "Nature will } \\
\text { fight back," "Animals deserve happy } \\
\text { lives" }\end{array}$ \\
\hline Human Resources & $\begin{array}{l}\text { The resources that nature provides to } \\
\text { humans are important to us. }\end{array}$ & $\begin{array}{l}\text { "It's our source of food and water," "It's } \\
\text { our home," "We need it." }\end{array}$ \\
\hline Human Enjoyment & $\begin{array}{l}\text { It's enjoyable, beautiful and helps } \\
\text { quality of life and societal progress. }\end{array}$ & $\begin{array}{l}\text { "To enjoy its beauty," "Quality of life" } \\
\text { "Because nature is awesome," "For a } \\
\text { better life" }\end{array}$ \\
\hline Human Health \& Survival & $\begin{array}{l}\text { To promote the physical health or sur- } \\
\text { vival of humans (specifically) }\end{array}$ & $\begin{array}{l}\text { "Protect humans from going extinct," } \\
\text { "For good health" }\end{array}$ \\
\hline Survival of All Life & To avoid cessation of all life on Earth & $\begin{array}{l}\text { "It is necessary for the survival of the } \\
\text { planet," "Life in general" }\end{array}$ \\
\hline Moral Imperative & $\begin{array}{l}\text { Ethical principles or religious tenets } \\
\text { hold it as important. }\end{array}$ & $\begin{array}{l}\text { "It's our duty to take care of God's } \\
\text { Earth," "It's wrong to destroy it." }\end{array}$ \\
\hline Future & $\begin{array}{l}\text { For our future and/or for the sake of } \\
\text { future generations }\end{array}$ & $\begin{array}{l}\text { "For our kids," "So it is there for future } \\
\text { generations to enjoy" }\end{array}$ \\
\hline Irreplaceability & Nature is irreplaceable and unique & $\begin{array}{l}\text { "We only have one," "Once it's gone } \\
\text { it's gone" }\end{array}$ \\
\hline
\end{tabular}

Other Valid Response Types (Included in Main Analyses)

Opposed
States opposition to the premise that nature should be protected.
"It's not," "Stop spreading liberal propaganda" 
Don't Know States they are uncertain or do not "Unsure," "I don’t know" know what to give as an answer.

\begin{tabular}{lll}
\hline $\begin{array}{l}\text { Invalid Response Types } \\
\text { (Excluded from Main Analyses) }\end{array}$ & \\
\hline Solutions & $\begin{array}{l}\text { The response prescribes solutions, ra- } \\
\text { ther than providing a reason why. }\end{array}$ & $\begin{array}{l}\text { "Bike more, drive less, plant trees," "Re- } \\
\text { cycle" }\end{array}$ \\
The response was too vague or broad & "Many," "Lots of reasons" \\
to represent a specific reason. & The response was not able be under- \\
stood by the coders, or a translation & "Because of the nature of safety." \\
error occurred. & $\begin{array}{l}\text { The respondent opted to not answer } \\
\text { the question. }\end{array}$ & [missing data], "N/A", \\
Refused & &
\end{tabular}

Figure 1

Frequencies of the Types of Reasons to Protect Nature, Overall and by Country
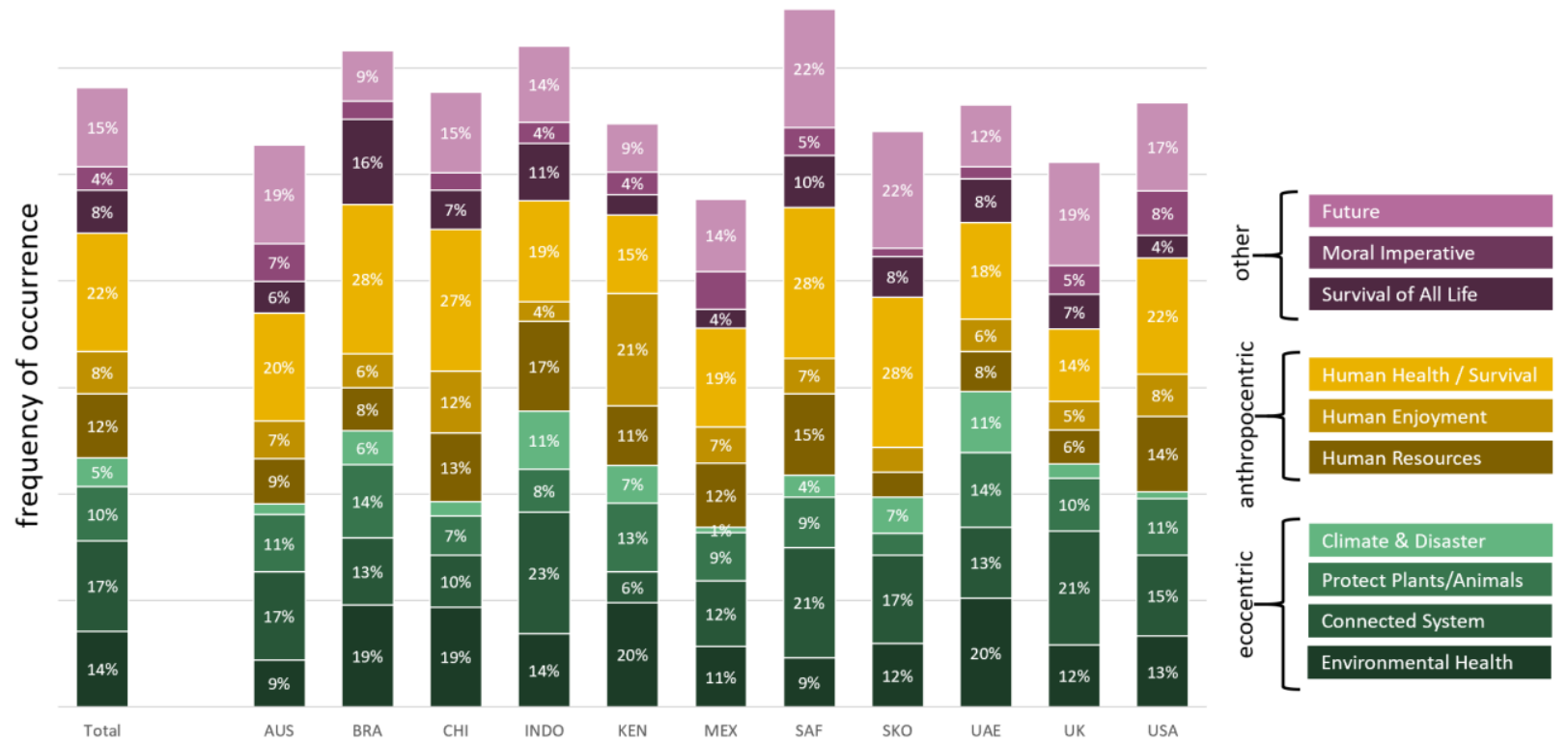

country

Note. The values are proportions calculated out of the total valid responses in each column group. The columns sum to more than $100 \%$ because some responses contained more than one type of reason to protect nature, in which case multiple reasons were tallied. Four types of valid responses (Nature's Autonomy; Irreplaceability; Don't Know; Opposed) are omitted from this figure because in no countries did any of these four types occur in more than $4 \%$ of responses $(\min =0 \%)$.

Informing RQ2 and RQ3, the proportional frequency of each type of reason indicates their respective prevalence as people's most important reasons to protect nature. A particularly interesting finding was the prevalence of both "Connected System" and "Future." About one in six (17\%) responses in the full international sample contained the code "Connected System," and this type of reason was most common in Indonesia (23\%), South Africa (21\%), and the United Kingdom (21\%). This finding indicates that concern about the delicate balance and interconnectivity of natural systems is one of the most prominent reasons why people feel we should protect nature. This finding also suggests value in advocacy strategies that aim to foster environmental concern and action by promoting "systems thinking" (Ballew et al., 2019; Goldberg, Gustafson, \& van der Linden, 2020).

Similarly, $15 \%$ of respondents across the full international sample said the most important reason to protect nature was for the sake of future generations, or to 
leave behind a positive legacy. This reason was common in South Africa (22\%), South Korea (22\%), Australia (19\%), and the United Kingdom (19\%), but was relatively rare in Brazil (9\%) and Kenya (9\%).

Overall, though, the most frequently stated reason to protect nature was "Human Health and Survival" a utilitarian rationale focusing on ensuring humans' physical health and avoiding extinction. This response was present in $22 \%$ of responses overall and was the most common response in South Korea (28\%), Brazil (28\%), South Africa (28\%), and China (27\%). But this pattern is not found in every country. For example, "Human Health and Survival" was found only half as often in the United Kingdom (14\%) and Kenya (15\%). Respondents from the United Kingdom were much more likely to include "Connected System" (21\%) in their response, and respondents from Kenya were more likely to mention "Human Enjoyment" (21\%) or "Environmental Health" (20\%).

The data show several other important differences between countries (Figure 1). For example, "Connected System" was nearly four times more frequent in Indonesia $(23 \%)$ than in Kenya (6\%) and twice as frequent as in China (10\%). Also, "Future" was about twice as common in South Korea (22\%) and South Africa (22\%) compared to Brazil (9\%) or Kenya (9\%).

Further, there are some countries (e.g., Indonesia, South Africa) in which "Human Resources" is far more frequently stated than "Human Enjoyment." But Kenya exhibits the opposite pattern-with "Human Enjoyment" (21\%) being nearly twice as frequent as "Human Resources" (11\%).

We also see that responses focusing on "Moral Imperative" (4\%) or "Nature's Autonomy" (2\%) were quite rare overall. The former is closely aligned with Chan et al.'s (2016) "relational" values while the latter corresponds with "intrinsic" values and Steg's (2007) normative goals. So, although much research shows normative goals, morality, and ethics are influential in environmental psychology, it seems people rarely mention these motives explicitly when asked to state their reasoning. One explanation for this could be that people underestimate the influence of norms (Cialdini, 2005; Jaeger \& Schultz, 2017; Nolan et al., 2008), or that they simply tended to interpret the survey question as referring to the tangible outcomes of protecting nature rather than to a moral or philosophical mandate for protecting nature. Regardless of their low prevalence in people's stated motives, social norms should still be a central focus of communicators, advocacy groups, and policymakers because of their powerful influence.

\section{Future Directions}

In sum, we find a wide variety of types of reasons to protect nature that people say are the most important. The development of this typology is itself an important asset because it reflects the unrestricted expressions of 6,000 diverse people around the world. While reasons such as "Human Health \& Survival," "Connected System," "Future," and "Environmental Health" were found to be the most common across the 11 countries in this analysis, we observe substantial differences in frequencies between countries.

Future research could investigate how each of these different types of motives tend to correspond with levels of pro-environmental attitudes and behaviors. It may be that people who give one type of reason (e.g., "Protect Plants and Animals") have stronger pro-environmental attitudes or behaviors than people who give other types (e.g., "Human Resources).

Also, more research is needed to determine why countries differ in their dominant rationale for protecting nature. There are myriad social, cultural, economic, political, and physical factors that could cause these differences - and it is not within the scope of this descriptive study to attempt to evaluate and defend those possible explanations.

When interpreting these results, readers should note that we found that four countries were affected by an apparent pattern of artificially duplicated responses (India $25 \%$, China 16\%, Indonesia 7\%, Kenya 6\%). While these cases were flagged and removed (and the India sample excluded entirely), we must still be consider the possibility that some of the China and Indonesia samples - both fielded fully online - may have been affected by bot activity. The Kenya sample, however, was conducted fully face-to-face, so bots are unlikely. But the pattern of responses (all in English, often with similar phrasing and structure) makes it seem likely that an interviewer paraphrased Kenyan participants' responses rather than participants entering their verbatim response themselves. This is certainly a limitation of the Kenyan sample, primarily because it's different from the data of the other countries and secondarily because it's not quite the same as hearing the word choice and detail used by the participant. But because the present study does not aim to study the exact words used in participants' responses, but rather to record the general themes and topics they reference, we feel this data is still useful in informing the research questions. Overall, this also points to the difficulty and tradeoffs in conducting international research at a large scale. Yet in the remaining eight countries (4,005 responses), we found only 78 instances of 
likely duplicate responses $(<2 \%)$, giving us high confidence in the quality of these data.

Readers should also consider that, although this typology is generated by the response data, it is still partially shaped by the authors' decisions when conducting the thematic analysis. Different typologies could be valid and useful, and we encourage researchers to explore these by using our publicly available dataset. Still, the limitations inherent to a thematic analyses must be considered in conjunction with the benefits, particularly in how this study studies environmental psychology by allowing people to speak in their own words.

Overall, this study provides rich qualitative insights at a large scale regarding the stated motives and rationales underlying people's desire for environmental action. In addition to informing theoretical understandings of environmental psychology, the findings of this study can improve the effectiveness of interventions (e.g., communication campaigns) by guiding them to resonate with the most prevalent motives for protecting nature within specific countries.

\section{Data Availability}

The data used for the main analyses $(N=6,000)$ are available for download on the Open Science Framework platform (https://osf.io/9xnz8/). This dataset contains the original text of all responses in their original languages, the English translations of those responses, and the codings given to each response by the human coders. The remaining random half of the dataset that was not analyzed for this project is available from the corresponding author. The project's OSF page also includes additional methods information describing the full typology development process, the codebook with coding rules and procedures for the qualitative analysis, and detailed explanations and examples for all types of content coding labels.

\section{References}

A Ajzen, I. (1991). The theory of planned behavior. Organizational Behavior and Human Decision Processes, 50(2), 179-211.

Adler, N. \& Stewart, J. (2007). The MacArthur scale of subjective social status. MacArthur Research Network on SES and Health. Retrieved from https://macses.ucsf.edu/research/psychosocial/subjective.php Ballew, M. T., Goldberg, M. H., Rosenthal, S. A., Gustafson, A., \& Leiserowitz, A. (2019). Systems thinking as a pathway to global warming beliefs and attitudes through an ecological worldview. Proceedings of the National Academy of Sciences, 116(17), 8214-8219.
Bogner, F. X., \& Wiseman, M. (1999). Toward measuring adolescent environmental perception. European Psychologist, 4(3), 139-151.

Chan, K. M., Balvanera, P., Benessaiah, K., Chapman, M., Díaz, S., Gómez-Baggethun, E., ... \& Turner, N. (2016). Opinion: Why protect nature? Rethinking values and the environment. Proceedings of the National Academy of Sciences, 113(6), 1462-1465.

Cialdini, R. B. (2005). Basic social influence is underestimated. Psychological Inquiry, 16(4), 158-161.

Clarke, V. \& Braun, V. (2014). Thematic analysis. In Encyclopedia of Critical Psychology (pp. 1947-1952). Springer, New York, NY.

Foddy, W. (1993). Constructing Questions for Interviews and Questionnaires: Theory and Practice in Social Research. United Kingdom: Cambridge University Press. Fransson, N., \& Gärling, T. (1999). Environmental concern: Conceptual definitions, measurement methods, and research findings. Journal of Environmental Psychology, 19(4), 369-382.

Goldberg, M. H., Gustafson, A., Rosenthal, S. A., \& Leiserowitz, A. (2021). Shifting Republican views on climate change through targeted advertising. Nature Climate Change, 11, 573-577.

Goldberg, M. H., Gustafson, A., Ballew, M. T., Rosenthal, S. A., \& Leiserowitz, A. (2019). A social identity approach to engaging Christians in the issue of climate change. Science Communication, 41(4), 442-463.

Goldberg, M. H., Gustafson, A., \& van der Linden, S.

(2020). Leveraging Social Science to Generate Lasting Engagement with Climate Change Solutions. One Earth, 3(3), 314-324.

Gustafson, A., Goldberg, M. H., Kotcher, J. E., Rosenthal, S. A., Maibach, E. W., Ballew, M. T., \& Leiserowitz, A. (2020). Republicans and Democrats differ in why they support renewable energy. Energy Policy, 141, 111448.

Hurst, K. \& Stern, M. J. (2020) Messaging for environmental action: the role of moral framing and message source. Journal of Environmental Psychology, 68, 101394.

Jaeger, C. M., \& Schultz, P. W. (2017). Coupling social norms and commitments: Testing the underdetected nature of social influence. Journal of Environmental Psychology, 51, 199-208.

Lazarsfeld, P. F. (1944). The controversy over detailed interviews - an offer for negotiation. Public Opinion Quarterly, 8(1), 38-60.

Lindenberg, S., \& Steg, L. (2007). Normative, gain and hedonic goal frames guiding environmental behavior. Journal of Social issues, 63(1), 117.

Luong, K. T., Garrett, R. K. \& Slater, M. D. (2019) Promoting persuasion with ideologically tailored science messages: a novel approach to research on emphasis framing. Science Communication, 41, 488-515.

Milfont, T. L, \& Duckitt, J. (2010). The environmental attitudes inventory: A valid and reliable measure to assess the 
structure of environmental attitudes. Journal of Environmental Psychology, 80-94.

https://doi.org/10.1016/j.jenvp.2009.09.001

Milfont, T. L. (2007). Psychology of Environmental Attitudes. The University of Auckland.

Nolan, J. M., Schultz, P. W., Cialdini, R. B., Goldstein, N. J., \& Griskevicius, V. (2008). Normative social influence is underdetected. Personality and Social Psychology Bulletin, 34(7), 913-923.

Pew Research Center (2021, July 30). Writing Survey Questions. https://www.pewresearch.org/our-methods/u-s-surveys/writing-survey-questions/

Steg, L., Bolderdijk, J. W., Keizer, K., \& Perlaviciute, G. (2014). An integrated framework for encouraging pro-environmental behaviour: The role of values, situational factors and goals. Journal of Environmental Psychology, 38, 104115.

Stern, P. C. (2000). Toward a coherent theory of environmentally significant behavior. Journal of Social Issues, 56(3), 407-424

Wolsko, C., Ariceaga, H. \& Seiden, J. (2016) Red, white and blue enough to be green: effects of moral framing on climate change attitudes and conservation behaviors. Journal of Experimental Psychology, 65, 7-19. 